\title{
Holistic sexuality post gynaecological cancer treatment: A review of recent literature
}

\begin{tabular}{|c|c|}
\hline $\begin{array}{l}\text { Authors: } \\
\text { Sorrel Pitcher } \\
\text { Tracey Adams } \\
\text { Leon van Wijk } \\
\text { Nazia Fakie }^{1,3} \\
\text { Rakiya Saidu }^{1,2} \\
\text { Lynette Denny } \\
\text { Jennifer Mooc }\end{array}$ & $\begin{array}{l}\text { (1) } \\
2 \text { (1) } \\
1,3 \text { (1) } \\
1,4 \text { (1) } \\
\operatorname{ley}^{1,5,6,7} \text { (1) }\end{array}$ \\
\hline \multicolumn{2}{|c|}{$\begin{array}{l}\text { Department of Obstetrics } \\
\text { and Gynaecology, University } \\
\text { of Cape Town, South Africa }\end{array}$} \\
\hline \multicolumn{2}{|c|}{$\begin{array}{l}\text { Department of } \\
\text { Gynaecological Oncology, } \\
\text { Groote Schuur Hospital, } \\
\text { South Africa }\end{array}$} \\
\hline \multicolumn{2}{|c|}{$\begin{array}{l}{ }^{3} \text { Department of Radiation } \\
\text { Oncology, Groote Schuur } \\
\text { Hospital, South Africa }\end{array}$} \\
\hline \multicolumn{2}{|c|}{$\begin{array}{l}{ }^{4} \text { Groote Schuur Hospital, } \\
\text { Cape town, South Africa }\end{array}$} \\
\hline \multicolumn{2}{|c|}{$\begin{array}{l}{ }^{5} \text { Cancer Research Initiative, } \\
\text { University of Cape Town, } \\
\text { South Africa }\end{array}$} \\
\hline \multicolumn{2}{|c|}{$\begin{array}{l}{ }^{6} \text { Women's Health Research } \\
\text { Unit, University of Cape } \\
\text { Town, South Africa }\end{array}$} \\
\hline \multicolumn{2}{|c|}{$\begin{array}{l}{ }^{7} \text { School of Public Health and } \\
\text { Family Medicine, University } \\
\text { of Cape Town, South Africa }\end{array}$} \\
\hline \multicolumn{2}{|c|}{$\begin{array}{l}\text { Corresponding author: } \\
\text { Jennifer Moodley, } \\
\text { jennifer.moodley@uct.ac.za }\end{array}$} \\
\hline \multicolumn{2}{|c|}{$\begin{array}{l}\text { Dates: } \\
\text { Received: } 05 \text { Apr. } 2018 \\
\text { Accepted: } 14 \text { May } 2018 \\
\text { Published: } 28 \text { June } 2018\end{array}$} \\
\hline \multicolumn{2}{|l|}{ Read online: } \\
\hline 口irg & $\begin{array}{l}\text { Scan this QR } \\
\text { code with your } \\
\text { smart phone or } \\
\text { mobile device } \\
\text { to read online. }\end{array}$ \\
\hline
\end{tabular}

Background: Sexual difficulties post gynaecological cancer treatment are commonplace and can impact multiple aspects of a woman's life. Yet, health care practitioners remain reluctant to discuss sexuality from a holistic perspective with their patients.

Aim: This article reviewed the literature on sexuality post gynaecological cancer treatment from the last 10 years. The aim was to understand research trends as well as identify gaps in the field.

Methods: The review was framed using the neo-theoretical framework of sexuality. A comprehensive literature search, using the electronic databases EBSCOHost, Ovid, Clinical Key and PubMed, was conducted for articles concentrating on sexuality after gynaecological cancer treatment, published from 2007 to 2017 in English.

Results: The results showed that the majority of the literature still approaches sexuality post treatment from a biomedical perspective with a focus on physical sexual functioning. However, there has been a slight shift towards understanding sexuality from a comprehensive standpoint, although there is a dearth of research relating to the psychological and relational aspects of sexuality.

Conclusion: Comprehensive sexuality post treatment should be given further consideration in South Africa, and our unique socio-cultural context ought to be taken into consideration. Additionally, interventions at multiple levels should be explored, such as broadening sexual health training within the medical curriculum, considering the development of holistic cancer clinics and widening the scope of research relating to gynaecological cancer care.

\section{Introduction}

Sexual well-being is an important quality of life factor, ${ }^{1}$ and women who have active and satisfying sexual relationships report higher levels of happiness and relationship fulfilment. ${ }^{2}$ Sexuality post gynaecological cancer treatment is important to consider as $40 \%-100 \%$ of gynaecological cancer patients will experience sexual complaints after treatment. ${ }^{3}$ These alterations vary in duration but may remain with a woman for life and thus can have a profound impact on well-being. ${ }^{4}$ Yet, health care professionals are often reluctant to discuss sexuality issues with their patients. ${ }^{5}$ When sexuality post gynaecological cancer treatment is discussed, it is often done so from a biomedical perspective that narrowly defines sexuality as the ability to have sexual intercourse and focuses predominantly on sexual dysfunction. ${ }^{6}$ Given South Africa's high rates of sexual violence and HIV and AIDS problems that have interpersonal and psychological impact - it is imperative to think of sexuality beyond physical acts. This article aims to review the literature on women's sexuality post gynaecological cancer treatment in order to understand it from a holistic perspective. It also outlines issues requiring further research and provides critical commentary. Improved understandings and conceptualisations of women's experiences of sexuality post treatment are imperative to improving patient-centred care and developing support programmes in South Africa.

This article utilised Cleary and Hegarty's neo-theoretical framework of sexuality ${ }^{7}$ to frame the review. This framework is based on Woods's ${ }^{8}$ inclusive understanding of sexuality and was elaborated on by incorporating theoretical and empirical literature. The neo-theoretical framework of sexuality consists of three interconnected elements: (1) sexual functioning, (2) sexual selfconcept and (3) sexual relationships.

Within this framework, sexual functioning is defined according to the sexual response cycle: desire, arousal and orgasm. Sexual desire is multifaceted but can be broadly conceptualised as a

How to cite this article: Pitcher S, Adams T, Van Wijk L, et al. Holistic sexuality post gynaecological cancer treatment: A review of recent literature. S. Afr. j. oncol. 2018;2(0), a40. https://doi.org/10.4102/sajo.v2i0.40

Copyright: ( 2 2018. The Authors. Licensee: AOSIS. This work is licensed under the Creative Commons Attribution License. 
motivational state in which people seek out sexual partners or experiences. ${ }^{9}$ Sexual arousal is outlined as physiological and psychological responses in anticipation of, or during, sexual activity. In women, this is signified by vasocongestion in the nipples, vulva, vagina and clitoris, as well as increased vaginal lubrication. Experiences of orgasm are highly subjective but are generally understood as the height of sexual pleasure during which pelvic contractions occur.

Sexual self-concept refers to psychological and cognitive constructs relating to how one experiences and understands one's sexual identity. It incorporates the sub-categories of sexual self-schema, body image and sexual esteem. Sexual self-schemas are ideas about one's sexuality that originate from past experiences and influence current sexual behaviour and information processing. ${ }^{10}$ They are understood as being either 'positive' or 'negative'. ${ }^{10}$ A positive sexual self-schema refers to viewing oneself as passionate and romantic and as a person who is open to new sexual experiences and is not limited by self-consciousness, embarrassment or negative feelings. Conversely, in a negative sexual self-schema, a person sees himself or herself as inhibited, conservative, selfconscious and embarrassed about his or her sexuality with limited passionate or romantic abilities. 'Body image' relates to how one mentally perceives and subjectively experiences his or her body. Feeling feminine is important for some women's body image, although how a woman interprets her femininity is dependent on socio-culturally produced ideas about gender and sexuality. For example, in numerous cultures, female reproductive organs are representative of femininity, motherhood and female sexuality. ${ }^{11}$ Lastly, sexual esteem is a type of self-esteem relating to one's sense of selfworth in terms of sexual behaviour and identity. ${ }^{7}$ It also refers to how one evaluates his or her sexual self.

Sexual relationships are characterised as any relation within which a person shares his or her sexuality with another or others. ${ }^{8}$ A fulfilling sex life is important to many couples as it is an opportunity for bonding, intimacy and quality time. Sexual difficulties post gynaecological cancer can therefore be stressful for couples as it can feel like a core part of the relationship has disappeared. These problems generally manifest in disparate intimacy needs and poor communication. ${ }^{12}$ The relationships category is thus delineated accordingly. Although intimacy and communication are the foundation of any relationship, in this article, they are spoken about in relation to sexual activities.

This article seeks to approach sexuality post treatment from a holistic perspective. However, it is necessary to outline the physical or physiological side effects to contextualise the other changes experienced. Physical side effects depend on the type of treatments received. Surgery to the genital area may not only be cosmetically disfiguring, but if it is followed by radiotherapy, additional physical changes may ensue, predominantly, loss of tissue elasticity. Radiotherapy for cervical cancer involves the application of both external radiation to the entire pelvic area and internal brachytherapy to boost doses to the cervix. Hence, possible anatomical changes include vaginal shortening, reduced vaginal elasticity, vaginal stenosis, genital swelling, pelvic nerve damage, clitoral fibrosis (or removal) and genital hypersensitivity. ${ }^{13}$ Vaginal bleeding after intercourse may occur from vaginal adhesions or atrophy after radiotherapy treatment, ${ }^{14}$ and, at the extreme end of this spectrum, vaginal necrosis with fistula formation may develop. Other physical or functional changes include dyspareunia, decreased vaginal lubrication, ${ }^{13}$ chronic pelvic pain, temporary or permanent colostomy, and premature menopause. ${ }^{15}$ Premature menopause involves symptoms that impact on sexual functioning - such as decreased libido and vaginal dryness - as well as loss of fertility ${ }^{16}$ which may have an emotional and socio-cultural impact. In addition, there are long-term consequences such as increased risk of osteoporosis, dementia and cardiovascular disease. Other related physical effects of pelvic therapy include acute and/or chronic diarrhoea, or radiation cystitis. ${ }^{17}$ Occasionally, the placement of an urostomy or colostomy is required. Fatigue is common and is often multifactorial in causation. ${ }^{14}$

\section{Methods}

A comprehensive literature search was conducted by accessing the online electronic database platforms: EBSCOHost, Ovid, Clinical Key and PubMed. Search terms included variations of the type of cancer, the geographical area of interest, the type of treatment and terms relating to sexuality (Table 1). The time frame was limited to literature published within the last 10 years to obtain an overview of the most recent research trends. Articles were included if they were full-text articles from peer-reviewed journals, published in English and focused on some aspect of female sexuality post gynaecological cancer treatment. However, given the small scope of the published literature in this area in South Africa, relevant grey literature from South Africa was also included. Exclusion criteria consisted of literature reviews or articles from non-peer-reviewed journals, studies not published in English and research that did not focus on female sexuality post gynaecological cancer treatment.

\section{Results}

The search yielded a total of 38 articles (Table 2). The majority

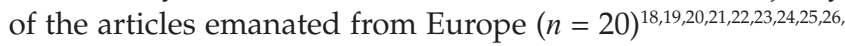
$27,28,29,30,31,32,33,34,35,36,37$ with the rest spread between North America $(n=7), 38,29,40,41,42,43,44$ Australia $(n=4)^{45,46,47,48}$ and Asia $(n=2) .{ }^{49,50}$ Five of the articles were from South Africa, ${ }^{51,52,53,54,55}$

\begin{tabular}{|c|c|}
\hline Field & Search terms \\
\hline Type of cancer & $\begin{array}{l}\text { 'gynecological cancer' OR 'gynaecological cancer', 'cervical } \\
\text { cancer', 'vulva cancer', 'vulval cancer', 'vulvar cancer', 'vaginal } \\
\text { cancer', 'uterine cancer', 'endometrial cancer', 'ovarian } \\
\text { cancer' and 'fallopian cancer' }\end{array}$ \\
\hline $\begin{array}{l}\text { Geographical area } \\
\text { of interest }\end{array}$ & 'South Africa' \\
\hline Type of treatment & $\begin{array}{l}\text { 'treatment', 'post-treatment', 'after treatment' 'radiotherapy', } \\
\text { 'radiation', 'chemotherapy', 'surgery' }\end{array}$ \\
\hline Sexuality & $\begin{array}{l}\text { 'sexuality', 'sexual function*' OR 'sexual dysfunction*', 'sexual } \\
\text { complications', 'sexual well-being', 'sexual health', 'sexual } \\
\text { pleasure', 'sexual relationships', 'intimacy', 'sexual } \\
\text { self-concept', 'communication' }\end{array}$ \\
\hline
\end{tabular}


TABLE 2: Summary of results.

\begin{tabular}{|c|c|}
\hline Variable & $n$ \\
\hline \multicolumn{2}{|l|}{ Geographical area of origin } \\
\hline Europe & 20 \\
\hline North America & 7 \\
\hline Australia & 4 \\
\hline Asia & 2 \\
\hline South Africa & 5 \\
\hline \multicolumn{2}{|l|}{ Methodology used } \\
\hline Quantitative & 22 \\
\hline Qualitative & 13 \\
\hline Mixed methods & 3 \\
\hline \multicolumn{2}{|l|}{ Articles published per year } \\
\hline 2007 & 5 \\
\hline 2008 & 4 \\
\hline 2009 & 5 \\
\hline 2010 & 3 \\
\hline 2011 & 5 \\
\hline 2012 & 1 \\
\hline 2013 & 5 \\
\hline 2014 & 3 \\
\hline 2015 & 1 \\
\hline 2016 & 4 \\
\hline 2017 & 2 \\
\hline \multicolumn{2}{|l|}{ Type of gynaecological cancer } \\
\hline Mixed & 14 \\
\hline Cervical & 12 \\
\hline Ovarian & 4 \\
\hline Vulvar & 1 \\
\hline Endometrial & 4 \\
\hline Not specified & 3 \\
\hline \multicolumn{2}{|l|}{ Focus of research } \\
\hline Sexual functioning & 25 \\
\hline $\begin{array}{l}\text { Sexual functioning plus another aspect of } \\
\text { sexuality }\end{array}$ & 15 \\
\hline $\begin{array}{l}\text { Sexual self-concept and sexual } \\
\text { relationships }\end{array}$ & 5 \\
\hline Holistic sexuality & 6 \\
\hline Other aspects of the treatment process & 2 \\
\hline
\end{tabular}

although two of these were grey literature. ${ }^{52,54}$ Most of the studies incorporated a variety of gynaecological cancers $(n=14)$ (e.g. endometrial, ovarian, cervical and vulvar) with almost as many focusing exclusively on cervical cancer ( $n=12$ ). In terms of content, sexual functioning was maintained as a focal point in the majority of studies $(n=25)$; however, many of these also investigated another aspect of sexuality post treatment $(n=15)$. Some studies did approach sexuality from a holistic perspective $(n=6)$, with one of them making use of the neo-theoretical framework of sexuality. ${ }^{26}$ The remaining articles looked at sexual relationships and aspects of sexual self-concept after treatment $(n=5)$. This variety in content marks a departure from previous literature trends that focused on biomedical aspects of sexual dysfunction. The results of the review are structured according to the different aspects of the neo-theoretical framework of sexuality.

\section{Sexual functioning}

In keeping with findings from previous decades, the majority of the studies in this review underscored how gynaecological cancer treatments can negatively affect one or more aspects of sexual functioning. Common problems include decreased desire; low frequency of sexual activity, sexual pleasure and satisfaction; high levels of discomfort; loss of vaginal elasticity; deep dyspareunia; vaginal dryness and shortening; and difficulty reaching orgasm. $18,20,21,22,23,24,27,29,30,32,34,35,38,39,40,42,43,49,50$ Side effects that manifest in other areas of the body - such as urinary or bowel dysfunction, and fatigue - also hinder sexual activity. ${ }^{18,21,22,48}$ These symptoms of sexual dysfunction persist for many years into survivorship. . $^{18,24}$

Articles included in this review continue the debate concerning which treatments have the greatest negative impact. ${ }^{7}$ Some studies suggest that radiotherapy leads to higher levels of sexual dysfunction than surgery or chemotherapy. ${ }^{22,24,27,38,47}$ Additionally, radiotherapy patients also score lower on global quality of life measures than women treated with surgery or adjuvant chemotherapy. ${ }^{23,47}$ However, other studies found no significant difference in sexual functioning between groups treated with radiotherapy and those not..$^{34,36,37,44}$ For example, endometrial cancer survivors $(n=246)$ who received adjuvant external beam radiotherapy showed no difference in sexual difficulties to those who did not undergo adjuvant treatment. ${ }^{37}$ Interestingly, while Greimel et al. ${ }^{23}$ found poorer quality of life scores among radiotherapy patients, there was no significant difference between sexual pleasure and sexual discomfort between the surgery, surgery/CT group and surgery/RT groups. One other study reported lower levels of sexual functioning post treatment in patients who had received surgery and adjuvant chemotherapy, or chemotherapy alone, compared to the surgery only group..$^{20}$ None of the South African studies compared sexuality outcomes across treatment modalities, and most of the participants in these studies had been treated for cervical cancer with external beam radiation and brachytherapy. ${ }^{51,52,53,54,55}$ However, the studies did make reference to the unique socio-demographic context in which such treatment occurs. Patients typically present in advanced stages where definitive radiotherapy is the treatment of choice. The higher doses received, compared with adjuvant radiotherapy doses as discussed in the studies above, may likely result in higher levels of sexual dysfunction. These patients are also typically younger, and thus the impact on fertility can be more distressing than for older women who have already completed their families.

Levels of sexual activity among gynaecological cancer survivors varied greatly, with studies reporting between $9 \%$ and $60 \%$ of participants being sexually active post treatment. These variations can be attributed to differences in age and treatment modality; however, non-cancer women were more sexually active than cancer survivors. ${ }^{39,50}$ Sexual activity decreases with age, ${ }^{56}$ and thus, studies with a higher mean age are more likely to report lower levels of sexual activity. ${ }^{34}$ Type of treatment can also impact level of sexual activity because, as outlined above, some forms of treatment are argued to have more severe sexual side effects than others. 


\section{Sexual self-concept}

There was only one study that explicitly stated investigating 'sexual self-concept' and that also included every aspect of the construct. ${ }^{26}$ In this study, mean scores on the measures relating to self-concept showed that the participants generally experienced a positive sexual self-schema, body image and sexual esteem post treatment. However, it was items on the body image measure that showed the most negative effects. A few other articles did explore one or more of the constructs under the sexual self-concept umbrella.

\section{Sexual self-schema}

It is theorised that differences in sexual functioning post treatment are related to a women's sexual self-schema, ${ }^{10,57}$ namely that women with a positive sexual self-schema pretreatment are more likely to report higher levels of functioning post treatment, whereas women with a negative sexual selfschema are more likely to report decreased functioning. One study in this review explored this correlation..$^{41}$ In regression analyses that controlled for patients' physical symptoms or signs, health status, socio-demographic variables, health status and level of partner's sexual difficulties, sexual selfschemas accounted for significant variance in current sexual functioning. It was also found that sexual self-schemas acted as a moderator between sexual satisfaction and psychological outcomes. This suggests that women with a positive sexual self-schema might be 'protected' from depressive symptoms even while experiencing low sexual satisfaction. However, having low sexual satisfaction combined with a negative sexual self-schema could increase a woman's likelihood for developing mental health issues. This suggests that sexual self-schemas can thus be a useful predictor for the possibility of sexual difficulties post treatment. However, no other studies have explicitly investigated this relationship, although women with lower levels of mental health concerns before and after treatment also report higher levels of sexual well-being post treatment. ${ }^{32}$

\section{Body image}

Of all the sexual self-concept constructs, body image after gynaecological cancer treatment has received the most attention in the literature. Interestingly, most of the studies were qualitative or mixed methods. The articles reviewed show that changes in body image post gynaecological cancer treatment are commonplace ${ }^{18,20,24,25,26,30,31,32,35,43}$ and relate to physical side effects and their corresponding perceived alterations in femininity. Physical changes to the body can be both external and internal. ${ }^{31}$ Visible, external changes include scarring, alopecia, weight changes and symptoms of premature menopause ${ }^{18,25,29,30,31,32,35}$ and negatively affect feelings of attractiveness, desirability and self-esteem. ${ }^{18,26,31,32,43}$ A discourse analysis of interviews with women post gynaecological cancer treatment found that women's experiences of bodily changes intersected with culturally dominant constructs of feminine beauty. ${ }^{31}$ The ability to conform to such ideals is seen as reflecting a women's desirability, sexual performance and youthfulness, and thus, any violation of these ideals because of treatment side effects results in a perceived decrease in social value. In South Africa, women reported excessive bleeding, smelly discharge and incontinence which led to feelings of humiliation and social stigmatisation. ${ }^{55}$ However, in another study, despite these drastic changes to their body, some women expressed gratitude for still being alive $\mathrm{e}^{32}$ and others experienced a change in body image but did not feel 'mutilated'. ${ }^{20}$ Another predominant theme within the studies related to the impact of internal, 'invisible' changes because of the loss of reproductive organs through surgery, for example, hysterectomy. ${ }^{25,29,30,31,32,35}$ The studies reviewed show that women experience varying reactions to the removal of their uterus. For some women, especially those who have completed their family or are beyond child-bearing age, having their uterus removed was preferable to having a breast removed because there was minimal impact on their feelings of external feminine expression..$^{25}$ Others were also relieved to be free from unpleasant symptoms. ${ }^{25,32}$ However, many experienced a sense of loss, in terms of having physically lost a part of their body, as well as a part of their sexual identity that was symbolised by their uterus. ${ }^{29,30,31,32,35}$ The latter concern appears to be linked with gender role functioning because of the fact that reproductive organs - particularly the uterus - are often cultural signifiers of femininity, fertility and motherhood. ${ }^{25,26,29,35}$ The loss of the uterus can therefore feel like the loss of one's ability to be feminine and a mother. ${ }^{35}$

\section{Sexual esteem}

There is a dearth of research that directly examines gynaecological cancer and sexual esteem as only two studies could be located. One study, as part of a holistic assessment of sexuality post treatment, measured sexual esteem using the Sexual Esteem Scale. ${ }^{26}$ The mean score indicated medium to low levels of sexual esteem. The other, a qualitative study, tenuously looked at sexual esteem in women with gynaecological cancer, although this was also used to refer to 'self-esteem'. ${ }^{19}$ This study aimed to better understand how ovarian cancer affects women's sexuality through semistructured, individual interviews. One of the key themes that emerged was how the treatment affected women's evaluation of their sexual identity. It is evident that this aspect of sexuality necessitates further research in the context of gynaecological cancer.

\section{Sexual relationships}

Studies that focused solely on sexual relationships postgynaecological cancer treatment were rare; however, they were often incorporated as part of broader areas of investigation.

\section{Intimacy and communication}

The articles reviewed, highlighted how diminished sexual intimacy can be a result of decreased frequency of intercourse, ${ }^{26}$ worries about being unattractive to partner or 
partners, ${ }^{31}$ fears of recurring disease, ${ }^{29}$ feelings of distance, ${ }^{43}$ unenjoyable intercourse ${ }^{48,51,53}$ and attachment anxiety. ${ }^{50}$ Women were also concerned that the lack of sexual intimacy would encourage partners to seek fulfilment elsewhere ${ }^{32,51,53}$ and thus reported that they often had intercourse even if they were in pain or felt no desire. ${ }^{29,51}$ These anxieties also emerge from wider, heteronormative assumptions around sex which construct penetrative vaginal intercourse as the only 'legitimate' way of signifying intimacy. ${ }^{58}$ Conversely, high levels of social support - particularly from a significant other - have been correlated with a higher quality of sex life among gynaecological cancer survivors ${ }^{28}$ and some women have reported loving support from partners post treatment. ${ }^{20,26}$ Furthermore, although sexual intimacy might decrease after treatment, the desire for other forms of intimacy such as being held, stroked or touched increases for some women, and thus, intimacy within relationships is not limited to sexual intercourse. ${ }^{26}$

Only one study was found that explored communication in intimate relationships post treatment. ${ }^{26}$ Findings from this study show that communication changes post treatment are not always negative, as 33\% $(n=25)$ of the participants found more time for quiet conversation with their partner since their cancer diagnosis and $49 \%(n=37)$ said that time for communication remained unchanged. Additionally, 55\% $(n=41)$ indicated that their comfort in discussing sexual matters with their partners remained unchanged.

\section{Discussion}

\section{The complexity of sexuality}

The above review has highlighted the multifaceted and complex ways that gynaecological cancer treatment affects female sexuality. Although the recent literature reflects a shift to more comprehensive understandings of sexuality, difficulties in sexual functioning remain the predominant focus, with aspects of sexual identity and relationships being secondary considerations. It is important to study all aspects of sexuality equally, as it is possible that women can be experiencing difficulties in one area, while satisfaction and pleasure in another. For example, Sekse et al. ${ }^{34}$ found that although the majority of their participants were sexually active, half of them expressed minimal satisfaction with this activity. Conversely, Moodley ${ }^{52}$ found that most of their participants $(61 \%)$ were also no longer sexually active post treatment; however, the majority reported a 'sense of satisfaction' on the sexual functioning measure, thereby highlighting that frequent sexual activity does not equate with pleasure or sexual satisfaction. In terms of frequency of intercourse, Greimel et al. ${ }^{23}$ found that even though $43.3 \%$ of their participants had not been sexually active in the last month, the reasons were not explicitly related to treatment side effects. Rather, the main reasons included not having a partner or not being in an intimate relationship and having a general lack of interest in sex. Some women also reported that they could not have sex because of their partner's health problems. Thus, sexual inactivity cannot exclusively be attributed to treatment side effects. It is imperative to be able to understand these complexities properly in order to develop more nuanced and accurate understandings of female sexuality in the context of gynaecological cancer. Furthermore, when holistically oriented studies are conducted, there is little exploration of how different sexuality constructs interact with each other.

\section{Methodological reflections}

There are a number of methodological issues that must be brought to attention within the existing literature. Firstly, in terms of operational definitions, sexual functioning is commonly defined in relation to partnered and/or penetrative sex. This limits sexual activity to certain acts and excludes those who have a sexual relationship with themselves (i.e. masturbation) or those couples who do not engage in penetrative intercourse. Secondly, the majority of the research is cross-sectional, and thus, longitudinal data are limited. It would be beneficial to collect data before, during and after treatment to be able to track changes in sexuality throughout women's cancer journeys. Lastly, most studies were conducted with samples consisting of white, middleaged women, in long-term relationships from upper middle income countries. This is not reflective of population groups that experience the highest burden of disease with regard to gynaecological cancer. ${ }^{59}$ Additionally, it should not be assumed that because a woman is not in long-term relationship, that sexual difficulties post-treatment do not affect her.

\section{Possibilities for interventions}

The results highlight significant gaps, locally and internationally, in the ways that sexuality post gynaecological cancer is approached within research and practice. There are thus opportunities for meaningful interventions. One such option is incorporating holistic understanding of sexuality into cancer care. Recently, some Canadian cancer centres have started clinics where physical, psycho-sexual and relationship issues are taken into consideration. ${ }^{60,61}$ Another possibility includes the employment of psycho-sexual therapists as part of a woman's clinical team who can work with her from diagnosis through to post treatment. Psycho-sexual support services in the form of educational booklets and group therapy have also been shown to be effective in helping women cope with the sexual side effects of treatment. ${ }^{62,63}$ Additionally, comprehensive sexuality teaching should be incorporated into doctors' training. However, these suggested interventions should not be implemented in South Africa without considering the context within which they will take place. For example, creating multidisciplinary cancer clinics within South Africa's public health care system might not be realistic given the already constrained resources. Furthermore, it is necessary to investigate what type of support cancer patients feel would be most beneficial for them. Therefore, further research is needed in this area within South Africa before effective interventions can be implemented. The authors of this article are currently conducting a study which seeks to understand sexuality post gynaecological cancer treatment 
from a holistic perspective and how women feel they can be better supported post treatment. It is hoped that the results of this study will contribute to greater understanding of this issue and, eventually, appropriate interventions.

\section{Conclusion}

As this review has shown, recent literature is slowly beginning to approach sexuality post gynaecological cancer treatment from a holistic perspective. However, there is still room for greater depth of understanding - particularly with regard to how various aspects of sexuality interact with each other. Further research is also needed with more diverse populations of women and to understand what type of interventions would be most effective within the South African context. However, interventions at the levels of teaching and practice should be considered as a starting point. Additionally, research around partners' experiences of the gynaecological cancer treatment process is essential for understanding the context within which women's healing takes place. Lastly, while this article approached sexuality from a holistic perspective, it is in no way an exhaustive description of female sexuality and there is much room for expansion in our understanding of sexuality in relation to gynaecological cancer. For example, it is also necessary to consider how gender roles and stereotypes, culture, location, ability and socio-economic context influence one's sexuality. There is thus room for more work in this area, particularly with how it relates to gynaecological cancer and patient care in South Africa.

\section{Acknowledgements}

The authors would like to thank the South African Medical Research Council (SAMRC) for providing the funding that made this research possible. They would also like to thank the broader Gynaecological Cancer Research Centre (GCRC) team for their support of their research endeavours relating to sexuality post cancer treatment.

\section{Competing interests}

The authors declare that they have no financial or personal relationships that may have inappropriately influenced them in writing this article.

\section{Authors' contributions}

S.P. was the project leader and J.M. was the senior author. S.P. was responsible for the data collection and analysis. J.M. and S.P. drafted the manuscript. All authors gave critical comment throughout the writing process. All authors were responsible for the conceptualisation and design of the project. All authors approved the final version to be published.

\section{Funding}

This research was made possible by funding from the South African Medical Research Council (SAMRC).

\section{References}

1. Bancroft J. Human sexuality and its problems. 3rd ed. Edinburgh: Churchil Livingstone;2009.

2. Davison SL, Bell RJ. The relationship between self reported sexual satisfaction and general well being in women. J Sex Med. 2009;6(10):2690-2697. https://doi.org/ 10.1111/j.1743-6109.2009.01406.x

3. Audette $C$, Waterman J. The sexual health of women after gynecologic malignancy. J Midwifery Women's Health. 2010;55(4):357-362. https://doi.org/10.1016/j. jmwh.2009.10.016

4. Tierney DK. Sexuality: A quality-of-life issue for cancer survivors. Semin Oncol Nurs. 2008;24(2):71-79. https://doi.org/10.1016/j.soncn.2008.02.001

5. Flynn KE, Reese JB, Jeffery DD, et al. Patient experiences with communication about sex during and after treatment for cancer. Psycho Oncol. 2012;21(6):594601. https://doi.org/10.1002/pon.1947

6. Hordern A. Intimacy and sexuality after cancer: A critical review of the literature. Cancer Nurs. 2008;31(2):E9-E17. https://doi.org/10.1097/01.NCC.0000305695. 12873.d5

7. Cleary V, Hegarty J. Understanding sexuality in women with gynaecological cancer Eur J Oncol Nurs. 2011;15(1):38-45. https://doi.org/10.1016/j.ejon.2010.05.008

8. Woods NF. Toward a holistic perspective of human sexuality: Alterations in sexual health and nursing diagnoses. Holist Nurs Prac. 1987;1(4):1-11. https://doi. org/10.1097/00004650-198708000-00004

9. Regan PC, Atkins L. Sex differences and similarities in frequency and intensity of sexual desire. Soc Behav Pers. 2006;34(1):95-102. https://doi.org/10.2224/ sbp.2006.34.1.95

10. Andersen BL, Cyranowski JM. Women's sexual self-schema. J Pers Soc Psych. 1994;67(6):1079. https://doi.org/10.1037/0022-3514.67.6.1079

11. Bachmann GA. Psychosexual aspects of hysterectomy. Women's Health Issues. 1990;1(1):41-49. https://doi.org/10.1016/S1049-3867(05)80015-5

12. Shell JA, Carolan M, Zhang Y, et al. The longitudinal effects of cancer treatment on sexuality in individuals with lung cancer. Oncol Nurs Forum. 2008;35(1):73-79. https://doi.org/10.1188/08.ONF.

13. Bergmark K, Åvall-Lundqvist E, Dickman PW, et al. Changes and sexuality in women with a history of cervical cancer. N Engl J Med. 1999;340(18):1383-1389. https://doi.org/10.1056/NEJM199905063401802

14. Lamb MA, Sheldon T. The sexual adaptation of women treated for endometrial cancer. Canc Pract. 1994;2(2):103-113.

15. Wilmoth MC, Spinelli A. Sexual implications of gynecologic cancer treatments. J Obs Gyn Neo Nurs. 2000;29(4):413-421. https://doi.org/10.1111/j.1552-6909. 2000.tb02064.x

16. Bourgeois-Law G, Lotocki R. Sexuality and gynaecological cancer: A needs assessment. Can J Hum Sex. 1999;8(4):231.

17. Katepratoom C, Manchana T, Amornwichet N. Lower urinary tract dysfunction and quality of life in cervical cancer survivors after concurrent chemoradiation versus radical hysterectomy. Int Urogynecol J. 2014;25(1):91-96. https://doi. org/10.1007/s00192-013-2151-6

18. Burns M, Costello J, Ryan-Woolley B, Davidson S. Assessing the impact of late treatment effects in cervical cancer: An exploratory study of women's sexuality. Euro J Can Car. 2007;16(4):364-372. https://doi.org/10.1111/j.1365-2354 2006.00743.x

19. Stead ML, Fallowfield L, Selby P, Brown JM. Psychosexual function and impact of gynaecological cancer. Best Pract Res Clin Obstet Gynaecol. 2007;21(2):309-320. https://doi.org/10.1016/j.bpobgyn.2006.11.008

20. Buković $D$, Silovski $H$, Silovski $T$, et al. Sexual functioning and body image of patients treated for ovarian cancer. Sex Disab. 2008;26(2):63-73. https://doi. org/10.1007/s11195-008-9074-z

21. Liavaag AH, Dørum A, Bjøro T, et al. A controlled study of sexual activity and functioning in epithelial ovarian cancer survivors: A therapeutic approach. Gynecol Oncol. 2008;108(2):348-354. https://doi.org/10.1016/j.ygyno.2007.10.009

22. Ditto A, Martinelli F, Borreani $C$, et al. Quality of life and sexual, bladder, and intestinal dysfunctions after class III nerve-sparing and class II radical hysterectomies: A questionnaire-based study. Int J Gynecol Canc. 2009;19(5):953957. https://doi.org/10.1111/IGC.0b013e3181a2d171

23. Greimel ER, Winter R, Kapp KS, Haas J. Quality of life and sexual functioning after cervical cancer treatment: A long term follow up study. Psycho Oncol. 2009; 18(5):476-482. https://doi.org/10.1002/pon.1426

24. Korfage IJ, Essink-Bot M-L, Mols F, et al. Health-related quality of life in cervical cancer survivors: A population-based survey. Int J Rad Oncol Bio Phys. 2009; 73(5):1501-1509. https://doi.org/10.1016/j.ijrobp.2008.06.1905

25. Sekse RJT, Raaheim M, Blaaka G, Gjengedal E. Life beyond cancer: Women's experiences 5 years after treatment for gynaecological cancer. Scand J Car Sci. 2010;24(4):799-807. https://doi.org/10.1111/j.1471-6712.2010.00778.x

26. Cleary V, Hegarty J, McCarthy G, et al. Sexuality in Irish women with gynecologic cancer. Oncol Nurs Forum. 2011;38(2):E87-E96. https://doi.org/10.1188/11.ONF.

27. Lind $H$, Waldenström $A C$, Dunberger $G$, et al. Late symptoms in long-term gynaecological cancer survivors after radiation therapy: A population-based cohort study. Brit J Canc. 2011;105(6):737-745. https://doi.org/10.1038/bjc.2011.315

28. Golbasi Z, Erenel AS. The quality of sexual life in women with gynaecological cancers. Arch Gyn Obs. 2012;285(6):1713-1717. https://doi.org/10.1007/s00404011-2210-5 
29. Bal M, Yilmaz S, Beji N. Sexual health in patients with gynecological cancer: A qualitative study. Sex Disab. 2013:31(1):83-92. https://doi.org/10.1007/s11195qualitative

30. Sekse RJT, Gjengedal E, Råheim M. Living in a changed female body after gynecological cancer. Health Care Women Int. 2013;34(1):14-33. https://doi.org/ $10.1080 / 07399332.2011 .645965$

31. Giacomoni C, Venturini E, Hoarau H, Guyon F, Conri V. How women with gynaecological cancer deal with treatment: Issues of visibility and invisibility. Gyn Obs Fert. 2014;42(11):795-799. https://doi.org/10.1016/j.gyobfe.2014.09.013

32. Pinar G, Kaplan S, Akalin A, et al. Evaluation of sexual dysfunction and affecting factors in Turkish women with gynecological cancer. Sex Disab. 2016;34(1):49-62. https://doi.org/10.1007/s11195-015-9411-y

33. Yaman Ş, Ayaz S. Psychological problems experienced by women with gynaecological cancer and how they cope with it: A phenomenological study in Turkey. Health SocWork. 2016;41(3):173-181. https://doi.org/10.1093/hsw/hlw030

34. Sekse RJT, Hufthammer KO, Vika ME. Sexual activity and functioning in women treated for gynaecological cancers. J Clin Nurs. 2017;26(3-4):400-410. https:// doi.org/10.1111/jocn.13407

35. Reis N, Beji NK, Coskun A. Quality of life and sexual functioning in gynecological cancer patients: Results from quantitative and qualitative data. Euro $J$ Oncol Nurs. 2010;14(2):137-146. https://doi.org/10.1016/j.ejon.2009.09.004

36. Becker M, Malafy $T$, Bossart $M$, et al. Quality of life and sexual functioning in endometrial cancer survivors. Gynecol Oncol. 2011;121(1):169-173. https://doi. org/10.1016/j.ygyno.2010.11.024

37. Nout RA, van de Poll-Franse LV, Lybeert MLM, et al. Long-term outcome and quality of life of patients with endometrial carcinoma treated with or without pelvic radiotherapy in the post operative radiation therapy in endometria carcinoma 1 (PORTEC-1) trial. J Clin Oncol. 2011;29(13):1692-1700. https://doi. org/10.1200/JCO.2010.32.4590

38. Donovan KA, Taliaferro LA, Alvarez EM, et al. Sexual health in women treated for cervical cancer: Characteristics and correlates. Gynecol Oncol. 2007;104(2): 428-434. https://doi.org/10.1016/j.ygyno.2006.08.009

39. Lindau ST, Gavrilova N, Anderson D. Sexual morbidity in very long term survivors of vaginal and cervical cancer: A comparison to national norms. Gynecol Oncol. 2007;106(2):413-418. https://doi.org/10.1016/j.ygyno.2007.05.017

40. Matulonis $\mathrm{U}$, Kornblith $\mathrm{A}$, Lee $\mathrm{H}$, et al. Long term adjustment of early stage ovarian cancer survivors. Int J Gynecol Canc. 2008;18(6):1183-1193. https://doi. org/10.1111/j.1525-1438.2007.01167.x

41. Carpenter KM, Andersen BL, Fowler JM, Maxwell GL. Sexual self schema as a moderator of sexual and psychological outcomes for gynecologic cance survivors. Arch Sex Behav. 2009;38(5):828-841. https://doi.org/10.1007/s10508008-9349-6

42. Tornatta JM, Carpenter JS, Schilder J, Cardenes HR. Representations of vaginal symptoms in cervical cancer survivors. Canc Nurs. 2009;32(5):378-384. https:// doi.org/10.1097/NCC.0b013e3181a54c39

43. Sacerdoti RC, Laganà L, Koopman C. Altered sexuality and body image after gynecological cancer treatment: How can psychologists help? Prof Psych: Res Prac. 2010;41(6):533-540. https://doi.org/10.1037/a0021428

44. Onujiogu N, Johnson T, Seo S, et al. Survivors of endometrial cancer: Who is at risk for sexual dysfunction? Gynecol Oncol. 2011;123(2):356-359. https://doi.org/10.1016/ j.ygyno.2011.07.035

45. Baldwin AE, Usher K. Going the distance: Experiences of women with gynaecological cancer residing in rural remote north Queensland. Int I Nurs Pract. 2008;14(4):322-328. https://doi.org/10.1111/j.1440-172X.2008.00705.x

46. Juraskova I, Butow P, Bonner C, Robertson R, Sharpe L. Sexual adjustment following early stage cervical and endometrial cancer: Prospective controlled multi-centre study. Psycho-Oncol. 2013;22(1):153-159. https://doi.org/10.1002/ pon.2066
47. Rowlands IJ, Lee C, Beesley VL, Webb PM, Group ANECS. Predictors of sexual wellbeing after endometrial cancer: Results of a national self-report survey. Support Care Canc. 2014;22(10):2715-2723. https://doi.org/10.1007/s00520-014-2263-7

48. Philp S, Mellon A, Barnett C, D'abrew N, White K. The road less travelled: Australian women's experiences with vulval cancer. Euro J Canc Care. 2017;26(1): 1-7.

49. Tangjitgamol S, Manusirivithaya S, Hanprasertpong J, et al. Sexual dysfunction in Thai women with early stage cervical cancer after radical hysterectomy. Int J Gynecol Canc. 2007;17(5):1104-1112. https://doi.org/10.1111/j.1525-1438.2007.00907.x

50. Hsieh CC, Chen CA, Hsiao FH, Shun SC. The correlations of sexual activity, sleep problems, emotional distress, attachment styles with quality of life: Comparison between gynaecological cancer survivors and noncancer women. J Clin Nurs. 2014;23(7-8):985-994. https://doi.org/10.1111/jocn.12232

51. Maree J, Mosalo A, Wright S. 'It depends on how the relationship was before you became ill': Black South African women's experiences of life partner support through the trajectory of cervical cancer. Euro J Canc Care. 2013;22(4):459-467. https://doi.org/10.1111/ecc.12051

52. Moodley A. Sexual function in women following radiotherapy or chemo-radiation for cervical cancer [unpublished dissertation]. Cape Town: University of Cape Town; 2013.

53. Ntinga SN, Maree JE. Living with the late effects of cervical cancer treatment A descriptive qualitative study at an academic hospital in Gauteng. SA J Gynaecol A descriptive qualitative
Oncol. 2015;7(1):21-26.

54. Fakunle IE. Sexual function in women after cervical cancer treatment at an academic hospital in Johanesburg, South Africa [unpublished dissertation]. Johannesburg: University of the Witwatersand; 2016.

55. Dzaka AD, Maree JE. Experiences of women receiving high dose rate brachytherapy for cervical cancer at an academic hospital. SA J Gynaecol Oncol. 2016;8(2):42-45. https://doi.org/10.1080/20742835.2016.1257174

56. Vistad I, Fosså SD, Kristensen GB, Mykletun A, Dahl AA. The sexual activity questionnaire: Pychometric properties and normative data in a Norwegian population sample. J Womens Health. 2007;16(1):139-148. https://doi.org/ 10.1089/jwh.2006.0052

57. Andersen BL. Surviving cancer: The importance of sexual self-concept. Med Ped Oncol. 1999;33(1):15-23. https://doi.org/10.1002/(SICI)1096-911X(199907)33: 1\%3C15::AID-MPO4\%3E3.0.CO;2-L

58. Gilbert E, Ussher JM, Perz J. Sexuality after gynaecological cancer: A review of the material, intrapsychic, and discursive aspects of treatment on women's sexual wellbeing. Maturitas. 2011;70(1):42-57. https://doi.org/10.1016/j.maturitas. 2011.06.013

59. Sankaranarayanan R, Ferlay J. Worldwide burden of gynaecological cancer: The size of the problem. Best Pract Res Clin Obs Gynae. 2006;20(2):207-225. https:// doi.org/10.1016/j.bpobgyn.2005.10.007

60. Strasser F, Sweeney C, Willey J, Benisch-Tolley S, Palmer JL, Bruera E. Impact of a half-day multidisciplinary symptom control and palliative care outpatient clinic in a comprehensive cancer center on recommendations, symptom intensity, and a comprehensive cancer center on recommendations, symptom intensity, and patient satisfaction: A
2004;1;27(6):481-491.

61. Zimmermann C, Seccareccia D, Clarke A, Warr D, Rodin G. Bringing palliative care to a Canadian cancer center: The palliative care program at Princess Margaret
Hospital. Support Care Canc. 2006;14(10):982-987. https://doi.org/10.1007/ Ho0520-006-0093-y

62. Sekse RJ, Blaaka G, Buestad I, Tengesdal E, Paulsen A, Vika M. Education and counselling group intervention for women treated for gynaecological cancer: Does it help?. Scand J Car Sci. 2014;28(1):112-121. https://doi.org/10.1111/ scs.12024

63. Lubotzky F, Butow P, Nattress K, et al. Facilitating psychosexual adjustment for women undergoing pelvic radiotherapy: Pilot of a novel patient psycho educational resource. Health Exp. 2016;19(6):1290-1301. https://doi.org/ $10.1111 /$ hex.12424 